\title{
Alcian Blue Staining Method
}

National Cancer Institute

\section{Source}

National Cancer Institute. Alcian Blue Staining Method. NCI Thesaurus. Code C92299.

A microscopy staining method that utilizes alcian blue, a cationic, water soluble coppercontaining phthalocyanine dye to determine the presence of acid mucopolysaccharides and glycosaminoglycans. 